\title{
Allograft inflammatory factor-1 (AIF-1) induces inflammatory mediator production via NF-KB signaling and impairs bovine mammary epithelial cells via mitochondrial pathway
}

\author{
Danru Yang \\ Southwest Minzu University \\ Yinghuan Wu \\ Southwest Minzu University \\ Yanying Zhao ( $\sim$ biozyy@163.com ) \\ Southwest Minzu University
}

Research

Keywords: Allograft inflammatory factor-1, bovine mastitis, bovine mammary epithelial cells, inflammation, cell apoptosis

Posted Date: June 4th, 2020

DOI: https://doi.org/10.21203/rs.3.rs-32056/v1

License: (c) (1) This work is licensed under a Creative Commons Attribution 4.0 International License.

Read Full License 


\section{Abstract \\ Background}

Bovine mastitis is the inflammatory response of the mammary gland with an utmost threat to the dairy industry worldwide. Cytokine networks fuel inflammation. The sensitive and subtle changes of the inflammatory cytokine network in healthy and mastitic bovine mammary gland may encourage the use of cytokines in the diagnosis and prognosis of bovine mastitis. Allograft inflammatory factor-1 (AIF-1) is a proinflammatory cytokine mainly secreted by immune cells and it plays a central role in the complex signaling network of inflammation activation. Therefore, we explored the possible role of bovine AlF-1 related to bovine mastitis in the present study.

\section{Results}

The average concentration of AIF-1 in milks suffering from mastitis was 2.5 fold of that in the healthy cows, while its value decreased in cows recovered from mastitis. Furthermore, recombinant bovine AIF-1 up-regulated TNF-a, IL-6, and monocyte chemoattractant protein 1 secretion from bovine mammary epithelial cells with NF-KB activating, then NF-KB signaling inhibitor BAY 11-7085 abolished the increase of these inflammatory cytokines secretion induced by AlF-1. Thereafter, AIF-1 impaired bovine mammary epithelial cell viability, induced cell membrane permeability and cell apoptosis with exacerbated nitric oxide and oxidative stress, activated caspase 3 , decreased mitochondrial membrane potential and intracellular ATP concentration.

\section{Conclusion}

These results indicated that AIF-1 prompted inflammation mediator production of bovine mammary epithelial cells via NF-KB signaling. Moreover, it damaged epithelial cells by depressing cell viability, inducing cell membrane permeability and cell apoptosis, which might be related to bovine mastitis.

\section{Background}

Bovine mastitis is the inflammatory response of the mammary gland to physiological and metabolic changes or injuries [1]. The disease is considered the utmost threat to the dairy industry worldwide through losses of milk production, milk of less quality, antibiotic use, labor, veterinarian, and culling of affected cow costs [2]. Mammary epithelial cells are the blood-milk barrier in mammary glands. In bovine mastitis, they serve as the first line of defense against pathogen invasion by initiating immune responses $[3,4]$. Exacerbated and/or sustained inflammation led to mammary epithelial cell dysfunction followed by increased the blood-milk barrier permeability and damage of surrounding extravascular tissues [5]. The inflammatory response is dictated by cytokines and numerous cytokines have been detected in the udders $[6,7]$. However, the distinct biological activity of cytokine in mastitis remains largely unknown. 
Allograft inflammatory factor-1 (AIF-1) is an inflammatory cytokine firstly identified in activated macrophages from rat cardiac allografts with chronic rejection [8]. In human, AlF-1 gene is located in the major histocompatibility complex (MHC) class III region, close to tumor necrosis factor-alpha (TNF-a), TNF- $\beta$, and NF-KB genes [9]. It is a $17 \mathrm{kDa}$ calcium-binding protein mainly produced by monocytes, macrophages, and lymphocytes $[10,11,12]$. Inflammatory processes, especially bacterial infection, increased AIF-1 expression [13]. Our previous study also revealed higher level of AIF-1 secreted into serum of mice suffering from insulitis than that in healthy mice and the antibody against AlF-1 prevented insulitis [14]. Furthermore, AIF-1 plays a central role in inflammation by influencing multiple key events such as activation of immune cells and the production of cytokines, chemokines and inflammatory mediators. These events form a complex signaling network in activation of inflammation $[15,16]$. In addition, AlF-1 proteins of different species share a high grade of amino acid sequence similarity, which indicates biological activity conservation [17]. Given the inflammatory nature of AIF-1, the effect of bovine AIF-1 on inflammatory responses and viability of mammary epithelial cells was explored in the present study.

\section{Materials And Methods}

\section{Assay the concentration of AlF-1 in milk}

The milk samples were obtained from 56 healthy midlactation Holstein-Friesian cows, 75 cows suffering from clinical mastitis and 23 cows recovering from clinical mastitis after antibiotic treatment from one dairy farm in Sichuan province of China on the basis of a clinical examination. The concentrations of AlF1 in milk samples were determined using a commercial bovine AIF-1 assay kit (No.YX-010907B,

Pengshida, Sichuan, China). All procedures were performed according to the manufacture's guideline. The optical absorbance at $450 \mathrm{~nm}$ was measured.

\section{Synthesis of bovine AlF-1 protein}

Spleen samples of bovines were harvested from a local slaughterhouse (Chengdu, Sichuan, China). Total RNA was extracted, CDNA was synthesized via reverse transcription and the entire open reading frame of bovine AIF-1 gene was amplified by PCR as previously described [18] using specific primers (sense: 5'ATGAGCGAAACTAGGGATTTAC-3', antisense: 5'-TCAGGGCAACTCAGAG

ATAGC-3') designed based on the nucleotide sequence of bovine AIF-1 (GenBank accession No. NM 173985). The PCR fragments were purified using agarose gel electrophoresis and cloned into PMD19-T vector (TaKaRa, Dalian, China), then transformed into competent E.coli DH5a cells (Novagen, Germany), and applied to DNA sequencing. Thereafter, bovine AIF-1 open reading frame was cloned into pET-32a plasmid at Ndel and Xhol sites. The recombinant plasmids (pET32a-AIF1) were also identified by DNA sequencing and transformed into competent BL21 (DE3) cells (Novagen, Germany) to express recombinant bovine AIF-1. The cells were cultured overnight, then fusion protein was induced by $0.8 \mathrm{mmol} / \mathrm{L}$ isopropyl-1-thio-- $\beta$-D-galactopyranoside (IPTG, Sigma, USA) and recombinant bovine AIF-1 
was purified using HisTrap ${ }^{\mathrm{TM}}$ HP (No. 17-5247-01, GE Healthcare, USA) according to the product description.

\section{Cell culture and treatment}

Bovine mammary gland epithelial cell line (MAC-T) was a generous gift from Professor Jinfeng Miao (Nanjing Agricultural University, China). The cells were grown in Dulbecco's Modified Eagle's Medium (DMEM, Hyclone, Fremont, CA, USA) supplemented with $10 \%$ fetal bovine serum (Gibco, USA) at $37^{\circ} \mathrm{C}$ in the humidified atmosphere of $5 \% \mathrm{CO}_{2} .0,0.1,1,10 \mathrm{nmol} / \mathrm{L}$ recombinant bovine AIF-1 protein was added into medium and incubated for 48 hours.

\section{Cell viability and apoptosis}

Cell Counting Kit-8 (CCK8, No.1706, Bioswamp, China) was applied to assess bovine mammary gland epithelial cell viability and proliferation. In detail, $3 \times 10^{3}$ cells was inoculated in 96 well cell culture plate overnight and exposed to $0,0.1,1$ or $10 \mathrm{nmol} / \mathrm{L}$ bovine AIF-1 for 48 hours, then CCK8 solution was added for 4 hours and the optical absorbance was estimated at $450 \mathrm{~nm}$. The data were shown as the percentage of viable cell count with AlF-1 treatment compared with that in control group. For cell apoptosis assay, the cells were stained with annexin V-FITC/PI (No. 1065, Beyotime, Nanjing, China). The cell percentage at different apoptotic stages was analyzed by flow cytometer (Beckman Coulter FC500, Brea, CA).

\section{Nitric oxide and reactive oxygen species (ROS) generation, inflammatory cytokines and lactate dehydrogenase (LDH) release}

At the same time, nitric oxide and reactive oxygen species (ROS) generation by the cells was measured with nitric oxide quantitation kit (A-013-2, Jiancheng, Nanjing, China) and cellular reactive oxygen species detection assay kit (No.PAB180052, Bioswamp, China), respectively. In addition, the supernatants were collected. The levels of TNF-a (No.HM10001, Bioswamp, China), interleukin 6 (IL6, No.HM10205, Bioswamp, China), monocyte chemoattractant protein 1 (MCP-1, No.HM10894, Bioswamp, China) and LDH (No. A020-1, Jiancheng, Nanjing, China) released from epithelial cells were also detected with the corresponding kits.

\section{Mitochondrial membrane potential $(\Delta \Psi \mathrm{m})$ and intracellular ATP content}

Using fluorescent probe JC-1 (No.180068, Beyotime, Nanjing, China), mitochondrial membrane potential was estimated [19]. In brief, the cells were incubated with $5 \mathrm{mg} / \mathrm{L} \mathrm{JC}-1$ for $20 \mathrm{~min}$ at $37^{\circ} \mathrm{C}$, then harvested by centrifugation for $5 \mathrm{~min}$ at $400 \mathrm{~g}$, washed thoroughly and suspended in $0.5 \mathrm{~mL}$ PBS. JC- 1 monomer and aggregate signals were detected by flow cytometry analysis and the ratio of aggregate/monomer fluorescent intensity was calculated to determine mitochondrial membrane potential. Additionally, the concentration of intracellular ATP was detected with an ATP assay kit (No. A095, Jiancheng, Nanjing, 
China). The cells were lysed in $200 \mu \mathrm{L}$ ATP assay buffer and the level of intracellular ATP was measured by chemiluminescence using ATP as standard (West Pico kit, Pierce, Loughborough, UK) and normalized to protein concentrations.

\section{Western blot}

The expression of cleaved caspase-3 and phosphorylation of IKBa in bovine mammary epithelial cells were assayed by western blot. In detail, total cellular were dissolved in lysis buffer containing protease and phosphatase inhibitors (Sigma, St. Louis, MO, USA). Then the proteins were applied to SDS-PAGE and transferred to polyvinylidene difluoride (PVDF) membranes (Whatman, London, UK). The membranes were blocked with $5 \% \mathrm{w} / \mathrm{v}$ bovine serum albumin in Tris- $\mathrm{HCl}$ buffer containing $0.1 \%$ Tween 20 . After that, the proteins on the membranes were immunologically reacted with the specific primary antibodies against cleaved caspase 3 (Asp175, No. 9661, 1:1000, Cell Signaling Techology, Danvers, MA, USA), pIKBa (Ser32, No. 2859, 1:1000, Cell Signaling Techology, Danvers, MA, USA), GAPDH (No. PAB36269, 1:1000, Bioswamp, China). Thereafter, the corresponding horseradish peroxidase conjugated secondary antibodies were added. Finally, specific immune complexes were assessed by chemiluminescence (West Pico kit, Pierce, Loughborough, UK).

\section{Statistical analysis}

The concentrations of bovine AIF-1 in milks were expressed as mean \pm standard deviation. Statistical analyses were performed with SPSS Statistics 17.0 software (SPSS Inc., Chicago, IL) and statistical differences between AIF-1 treatment groups and control group were determined by one-way ANOVA. A value of $P<0.05$ was considered as statistical significance.

\section{Results}

\section{The concentration of AIF-1 in milk with mastitis}

Sandwich ELISA was carried out to measure the concentrations of AIF-1 in milk with mastitis. As presented in Fig. 1, the average concentration of AlF-1 in milks suffering from mastitis was $426.2 \pm$ $9.4 \mu \mathrm{g} / \mathrm{L}$, significantly higher than that in the healthy cows $173.1 \pm 6.8 \mu \mathrm{g} / \mathrm{L}(P<0.001)$, while antibiotic treatment decreased the value to $207.7 \pm 4.3 \mu \mathrm{g} / \mathrm{L}(P<0.001)$ in cows recovered from mastitis. The results suggest that AIF-1 is a circulatory protein and it might be related to bovine mastitis.

\section{Preparation of bovine AlF-1 protein}

To further investigate the possible role of AIF-1 associated with bovine mastitis, recombinant bovine AIF-1 protein was prepared. First, bovine AIF-1 gene was cloned by RT-PCR and the deoxynucleotide sequence was identical with that submitted in Genebank No. NM 173985.2. Bovine AlF-1 protein contains 147 amino acids, which shares $91.2 \%$ similarity with human AIF-1 protein. Then bovine AIF-1 gene was expressed by E.coli BL21(DE3) cells. The fusion protein containing 6 histidine tag was purified by $\mathrm{Ni}^{2+}$ charged column and eluted by $100 \mathrm{mmol} / \mathrm{L}$ imidazole. Then, the fraction was assessed with SDS-PAGE 
as shown in Fig. 2. The purified protein with expected molecular weight (17 kDa), indicated by an arrow, was used in the following cell experiments.

\section{Inflammation in bovine mammary epithelial cells induced by bovine AlF-1}

As a part of the immune system, mammary epithelial cells play a critical role in bovine mastitis and mediate the innate and adaptive immune responses in the mammary gland by secreting proinflammatory cytokines and chemokines, including TNF- $a$, IL-6, MCP-1 or promoting lymphocyte responses [20, 21, 22]. In the present study, bovine AIF-1 potentially promoted IL-6, TNF- $a$, MCP-1 secretion from bovine mammary epithelial cells (Fig. 3A, B, C). Thus, bovine AIF-1 promoted proinflammatory cytokine release from mammary epithelial cells, further might recruit neutrophils to mammary gland. In addition, TNF-a and IL- 6 belong to key signaling molecules of the downstream NF- $\kappa$ B signaling pathway [23]. To understand the molecular mechanism of bovine AIF-1 induced expression of inflammatory cytokines, the NF-KB activation was analyzed by western blot. As shown in Fig. 3D, AIF-1 induced ІкBa phosphorylation, which suggested that AIF-1 activated NF-kB signaling. Furthermore, an irreversible inhibitor of NF-KB activation and IKBa phosphorylation, BAY 11-7085 (HY-10257, MedChemExpress, USA) depressed $10 \mathrm{nmol} / \mathrm{L}$ bovine AIF-1 protein induced up-regulation of IL-6, TNF-a and MCP-1. The results indicated AIF-1 promoted inflammatory mediator production of bovine mammary epithelial cells via NF-kB signaling activation.

\section{Mammary epithelial cell viability and cell membrane permeability}

In mastitis, exacerbated inflammation would induce epithelial dysfunction [5], therefore bovine mammary epithelial cell viability was estimated with CCK8. After 48-hour challenge, AIF-1 significantly decreased cell viability in a dose dependent manner as shown in Fig. 4A. The ultimate consequence of impairment of cell viability is mainly cell death including cell necrosis, apoptosis and/or autophagy [24]. Necrosis is characterized by loss of cell membrane integrity, release of cellular contents such as LDH as described above. Moreover, AIF-1 increased LDH release through cell membrane (Fig. 4B), implicating that AIF-1 increased mammary epithelial cell membrane permeability, and resulted in cell death.

\section{Cell apoptosis}

Then the cell apoptosis was investigated using annexin V-FITC/PI staining. The results in Fig. 5A revealed that AIF-1 significantly induced mammary epithelial cell apoptosis, especially increasing the percentage of cells at the late apoptotic stage. Excessive ROS can induce cell apoptosis via both the extrinsic and intrinsic pathways [25]. In the present study, AlF-1 promoted ROS and NO production (Fig. 5B, C). Overproduced NO can react with superoxide anion to form peroxynitrite causing DNA damage, lipid peroxidation, and mitochondria dysfunction, which therefore triggers cell apoptosis or necrosis [26]. 
Furthermore, it activated caspase 3 (Fig. 5D), which is essential for apoptotic body formation [27]. Therefore, AlF-1 induced mammary epithelial cell apoptosis.

\section{Mitochondria dysfunction}

Since AIF-1 induced cell apoptosis by activation of caspase 3, the mitochondria function was assessed. AlF-1 impaired mitochondrial membrane potential as evidenced via decreased ratio of JC-1 aggregates/JC-1 monomers (Fig. 6A-D), and by consequence, it further decreased intracellular ATP concentration (Fig. 6E). These data indicated that AlF-1 depressed mitochondrial function, which contributed to cell apoptosis.

\section{Discussion}

Bovine mastitis is the inflammatory response in the mammary gland [28], many cytokines are immunomodulatory proteins as inflammatory mediators. But the key cytokines associated with bovine mastitis have not been clearly elucidated. AIF-1 plays a central role in immune regulation and it is overexpressed in a vast array of inflammatory diseases such as allograft rejection [29], autoimmune diseases [14], inflammatory vasculopathy [30] and cancer [31]. In the present study, the concentrations of AlF-1 also increased in milks suffering from clinical mastitis and decreased in the cows recovered from clinical mastitis, which indicated AlF-1 might be related to bovine mastitis.

Given that epithelial cells pay important role in regulating the mammary gland health and disease [3]. In mastitis, mammary epithelial cells secrete inflammatory cytokines, chemokines, resulting in leukocyte recruitment and activation [4]. It has been reported that these cytokines play important roles in the pathogenesis of mastitis by amplifying the inflammatory response and inducing the migration of immunocytes into the infected area [32]. AlF-1 up-regulated inflammatory cytokine TNF-a, IL-6; chemokine MCP-1 production in mammary epithelial cells. The results were agreed with that mouse AIF-1 augmented production of IL- 6 and MCP-1 in macrophages [33. 34]. Mechanistically, mouse AIF-1 supported activation of the NF-KB pathway in the monocyte/macrophage, a key regulator involved in inflammation [35]. In our study, bovine AIF-1 also activated NF-KB and NF-KB inhibitor abolished the up-regulation of these inflammatory cytokines. Therefore, AIF-1 boosted inflammation mediator production in bovine mammary epithelial cells via NF-KB signaling. Sustained inflammatory reaction was considered to induce epithelial cell dysfunction [5].

Then, the effect of bovine AIF-1 on mammary epithelial cell viability was assayed. AlF-1 impaired epithelial cell viability, enhanced the permeability of the cell membrane and destroyed the integrity of mammary epithelial cells. The layer of mammary epithelial cells establishes the blood-milk barrier and the blood-milk barrier is essential for protecting mammary gland from the external environment. Destruction of the blood-milk barrier aggravates pathogen infection and promotes the development of mastitis [36]. 
Inflammation, oxidative response, apoptosis et al constitute the major defense networks that let mammary epithelial cells to survive under pathological stimuli [37]. AlF-1 induced nitric oxide and reactive oxygen species generation, which resulted into cell apoptosis, the results were consistent with our previous report that AIF-1 indicated rat insulinoma INS-1 cell line apoptosis via nitric oxide production [37]. In addition, exogenous AIF-1 treatment induced inflammation and oxidative stress in mouse mesothelial cells [38]. But AIF-1 supported macrophage survival, limited necrosis and apoptosis of mouse macrophages [35, 39]. Thus, AIF-1 might be a multifunctional protein with different effect on different cells. The main physiological source of reactive species production within most cells is the mitochondria. Furthermore, mitochondrial function was explored and it was not surprising that mitochondrial membrane potential and intracellular ATP concentration was decreased by AIF-1. On the other hand, western blot analysis suggested the promotion of caspase-3 activation. Likewise, similar effects on mitochondria and caspase-3 activity have been proved in the Nocardia from bovine mastitis-induced mammary epithelial cell apoptosis [40]. Altogether, these findings indicated that AIF-1 induce apoptosis of bovine mammary epithelial cells mediated by mitochondrial pathway.

\section{Conclusions}

The concentration of AIF-1 increased in milks with mastitis. Furthermore, it prompted inflammatory cytokines secretion of mammary epithelial cells via activation of NF-kB. Thereafter, it induced NO production and oxidative stress followed by decreasing cell viability, triggering cell necrosis and apoptosis by mitochondrial pathway. Therefore, AlF-1 induced inflammatory mediator production and dysfunction of bovine mammary epithelial cells, which may be related to bovine mastitis.

\section{Declarations}

\section{Funding}

This work was jointly supported by the National Natural Science Foundation of China (No. 31400794), Sichuan Province Science Funds for Distinguished Young Scholar (2019JDJQ0017) and Fundamental Research Funds for the Central Universities, Southwest Minzu University (2019XMJXPY08).

\section{Authors' contributions}

YZ conceived and designed the experiments. DY and YW performed the experiments and contributed data analysis. All authors have read and approved the final version of manuscript.

\section{Ethics approval and consent to participate}

Not applicable

\section{Consent for publication}

Not applicable 


\section{Competing interests}

The authors declare that they have no competing interests.

\section{References}

1. Viguier C, Arora S, Gilmartin N, Welbeck K, O'kennedy R. Mastitis detection. current trends and future perspectives. Trends Biotechnol. 2009;27:486-93.

2. Ruegg PL. A 100-Year Review: Mastitis detection, management, and prevention. J Dairy Sci. 2017;100(12):10381-97.

3. Guidry AJ, O'Brien CN, Douglass LW. A bovine mammary endothelial/epithelial cell culture model of the blood/milk barrier. Can J Vet Res. 1998;62:117-21.

4. Günther J, Esch K, Poschadel N, Petzl W, Zerbe H, Mitterhuemer S, Blum H, Seyfert HM. Comparative kinetics of Escherichia coli- and Staphylococcus aureus-specific activation of key immune pathways in mammary epithelial cells demonstrates that $S$. aureus elicits a delayed response dominated by interleukin-6 (IL-6) but not by IL-1 A or tumor necrosis factor alpha. Infect Immun. 2010;79:695-707.

5. Ryman VE, Packiriswamy N, Sordillo LM. Role of endothelial cells in bovine mammary gland health and disease. Anim Health Res. 2015;16:135-49.

6. Alluwaimi AM. The cytokines of bovine mammary gland: prospects for diagnosis and therapy. Res Vet Sci. 2004;77:211-22.

7. Bochniarz M, Zdzisińska B, Wawron W, Szczubiał M, Dąbrowski R. Milk and serum IL-4, IL-6, IL-10, and amyloid A concentrations in cows with subclinical mastitis caused by coagulase-negative staphylococci. J Dairy Sci. 2017;100:9674-80.

8. Utans U, Arceci RJ, Yamashita Y, Russell ME. Cloning and characterization of allograft inflammatory factor-1: a novel macrophage factor identified in rat cardiac allografts with chronic rejection. $\mathrm{J}$ Clin Invest. 1995;95:2954-62.

9. Iris FMJ, Bougueleret L, Prieur S, Caterina D, Primas G, Perrot V, Jurka J, Rodriguez-Tome P, Claverie $\mathrm{JM}$, Dausset J, Cohen D. Dense Alu clustering and a potential new member of the NF-kB family within a 90 kilobase HLA class III segment. Nat Genet. 1993;3:137-45.

10. Utans U, Quist WC, McManus BM, Wilson JE, Arceci RJ, Wallace AF, Russell ME. Allograft inflammatory factory-1. A cytokine-responsive macrophage molecule expressed in transplanted human hearts. Transplantation. 1996;61:1387-92.

11. Nagakawa Y, Nomoto S, Kato Y, Montgomery RA, Williams GM, Klein AS, Sun Z. Over-expression of AIF-1 in liver allografts and peripheral blood correlates with acute rejection after transplantation in rats. Am J Transplant. 2004;4:1949-57.

12. Del Galdo F, Maul GG, Jimenez SA, Artlett CM. Expression of allograft inflammatory factor 1 in tissues from patients with systemic sclerosis and in vitro differential expression of its isoforms in response to transforming growth factor beta. Arthritis Rheum. 2006;54:2616-25. 
13. Orsmark C, Skoog T, Jeskanen L, Kere J, Saarialho-Kere U. Expression of allograft inflammatory factor-1 in inflammatory skin disorders. Acta Derm Venereol. 2007;87:223-7.

14. Zhao YY, Huang XY, Chen ZW. Daintain/AIF-1 (Allograft Inflammatory Factor-1) accelerates type 1 diabetes in NOD mice. Biochem Biophys Res Comm. 2012;427:513-7.

15. Liu GW, Mai HX, Jiang LL, Zhao Y. Allograft inflammatory factor-1 and its immune regulation. Autoimmunity. 2007;40:95-102.

16. Sikora M, Kopeć B, Piotrowska K, \&Pawlik A. Role of allograft inflammatory factor-1 in pathogenesis of diseases. Immunol Lett. 2019. doi:10.1016/j.imlet.2019.12.002.

17. Zhao YY, Yan DJ, Chen ZW. Role of AlF-1 in the regulation of inflammatory activation and diverse disease processes. Cell Immunol. 2013;284:75-8.

18. Zhao YY, Lin YQ, Xu YO. Functional identification of allograft inflammatory factor 1 like gene (AIF1L) in Luning chicken. Animal Biotechnology. 2018;29:234-40.

19. Feng F, Ren Q, Wu S, Saeed M, Sun C. Hoxa5 increases mitochondrial apoptosis by inhibiting Akt/mTORC1/S6K1 pathway in mice white adipocytes. Oncotarget. 2017;8:95332-45.

20. Oviedo-Boyso J, Valdez-Alarcon JJ, Cajero-Juarez M, Ochoa-Zarzosa A, López-Meza JE, Bravo-Patiño A, Baizabal-Aguirre VM. Innate immune response of bovine mammary gland to pathogenic bacteria responsible for mastitis. J Infect. 2007;54:399-409.

21. Stelwagen K, Carpenter E, Haigh B, Hodgkinson A, Wheeler TT. Immune components of bovine colostrum and milk. J Anim Sci. 2009;87:3-9.

22. Gilbert FB, Cunha P, Jensen K, Glass EJ, Foucras G, Robert-Granié C, Rupp R, Rainard P. Differential response of bovine mammary epithelial cells to Staphylococcus aureus or Escherichia coli agonists of the innate immune system. Vet Res. 2013;44:40.

23. Huang S, Rutkowsky JM, Snodgrass RG, Ono-Moore KD, Schneider DA, Newman JW, Adams SH, Hwang DH. Saturated fatty acids activate TLR-mediated proinflammatory signaling pathways. J Lipid Res. 2012;53:2002-13.

24. Orrenius S, Nicotera P, Zhivotovsky B. Cell death mechanisms and their implications in toxicology. Toxicol Sci. 2011;119:3-19.

25. Lamkanfi M, Dixit VM. Manipulation of host cell death pathways during microbial infections. Cell Host Microbe. 2010;8:44-54.

26. Pacher P, Beckman JS, Liaudet L. Nitric oxide and peroxynitrite in health and disease. Physiol Rev. 2007;87:315-424.

27. Porter G, Jänicke RU. Emerging roles of caspase-3 in apoptosis. Cell Death Differ. 1999;6:99-104.

28. Mushtaq S, Shah AM, Shah A, Lone SA, Hussain A, Hassan QP, Ali MN. Bovine mastitis: An appraisal of its alternative herbal cure. Microb Pathog. 2018;114:357-61.

29. Autieri MV, Kelemen S, Thomas BA, Feller ED, Goldman BI, Eisen HJ. Allograft inflammatory factor-1 expression correlates with cardiac rejection and development of cardiac allograft vasculopathy. Circulation. 2002;106:2218-23. 
30. Kelemen SE, Autieri MV. Expression of allograft inflammatory factor- 1 in T lymphocytes: a role in Tlymphocyte activation and proliferative arteriopathies. Am J Pathol. 2005;167:619-26.

31. Liu S, Tan WY, Chen QR, Chen XP, Fu K, Zhao YY, Chen ZW. Daintain/AlF-1 promotes breast cancer proliferation via activation of the NF-kB/cyclin D1 pathway and facilitates tumor growth. Cancer Sci. 2008;99:952-7.

32. Wang W, Hu X, Shen P, Zhang N, Fu Y. Sodium houttuyfonate inhibits LPS-induced inflammatory response via suppressing TLR4/NF-KB signaling pathway in bovine mammary epithelial cells. Microb Pathog. 2017;107:12-6.

33. Watano K, Iwabuchi K, Fujii S, Ishimori N, Mitsuhashi S, Ato M, Kitabatake A, Onoé K. Allograft inflammatory factor- 1 augments production of interleukin- $6,-10$ and -12 by a mouse macrophage line. Immunology. 2001;104:307-16.

34. Tian Y, Kelemen SE, Autieri MV. Inhibition of AIF-1 expression by constitutive siRNA expression reduces macrophage migration, proliferation, and signal transduction initiated by atherogenic stimuli. Am J Physiol Cell Physiol. 2006;290:C1083-91.

35. Egaña-Gorroño L, Chinnasamy P, Casimiro I, Almonte VM, Parikh D, Oliveira-Paula GH, Jayakumar S, Law C, Riascos-Bernal DF, Sibinga NES. Allograft inflammatory factor-1 supports macrophage survival and efferocytosis and limits necrosis in atherosclerotic plaques. Atherosclerosis. 2019;289:184-94.

36. Wall SK, Hernández-Castellano LE, Ahmadpour A, Bruckmaier RM, Wellnitz O. Differential glucocorticoid-induced closure ofthe blood-milk barrier during lipopolysaccharide-and lipoteichoic acid-induced mastitis in dairy cows. J Dairy Sci. 2016;99:7544-53.

37. Li C, Li L, Chen K, Wang Y, Yang F, Wang G. UFL1 alleviates lipopolysaccharide-induced cell damage and inflammation via regulation of the TLR4/NF-KB pathway in bovine mammary epithelial cells. Oxid Med Cell Longev. 2019;10:6505373.

38. Huang XY, Zhao YY, Jia SH, Yan DJ, Chen ZW. Effects of daintain/AIF-1 on $\beta$ cell dysfunction in INS-1 cells. Biosci Biotechnol Biochem. 2011;75:1842-4.

39. Yang ZF, Ho DW, Lau CK, Lam CT, Lum CT, Poon RT, Fan ST. Allograft inflammatory factor-1 (AIF-1) is crucial for the survival and pro-inflammatory activity of macrophages. Int Immunol. 2005;17:1391-7.

40. Chen W, Liu Y, Zhang L, Gu X, Liu G, Shahid M, Gao J, Ali T, Han B. Nocardia cyriacigeogica from bovine mastitis induced in vitro apoptosis of bovine mammary epithelial cells via activation of mitochondrial-caspase pathway. Front Cell Infect Microbiol. 2017;7:194.

\section{Figures}




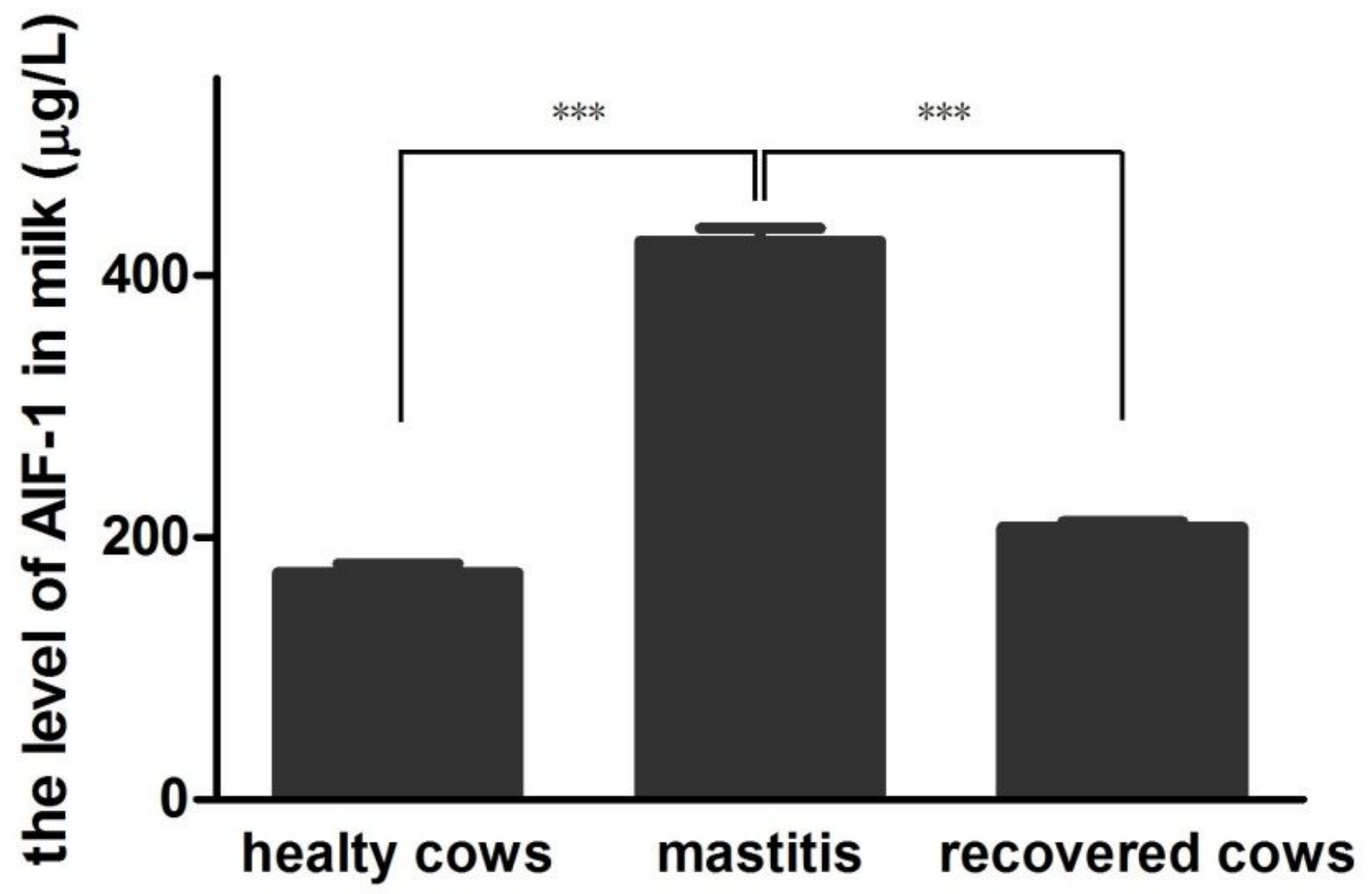

Figure 1

The concentrations of AlF-1 in milks. Milk samples were obtained from 56 healthy midlactation HolsteinFriesian cows, 75 cows suffering from clinical mastitis and 23 cows recovering from clinical mastitis after antibiotic treatment from one dairy farm in Sichuan province of China. The concentrations of AIF-1 in milk samples were determined using a commercial bovine AlF-1 assay kit. *** $P<0.001$. 


\section{marker}

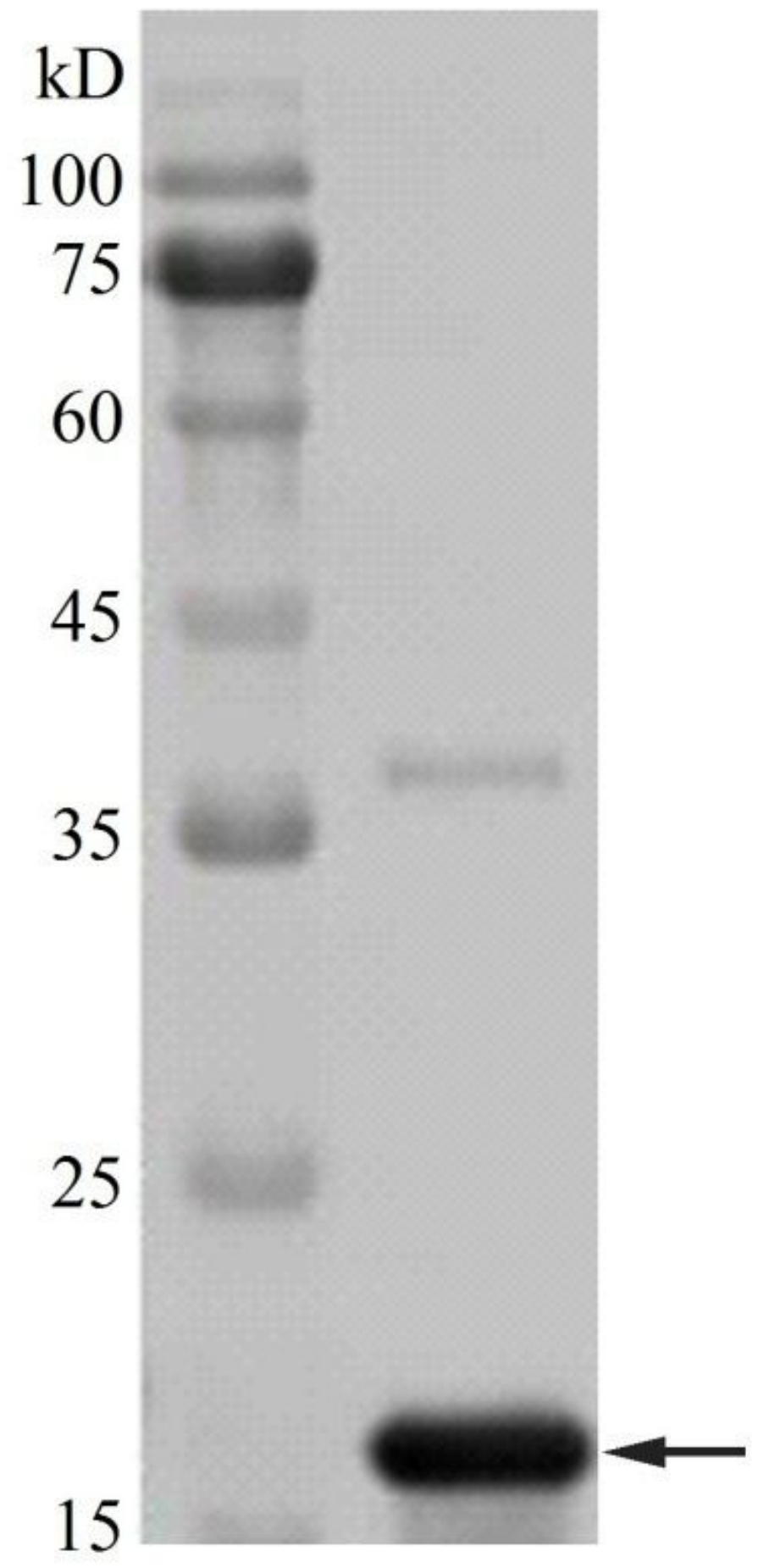

\section{Figure 2}

Preparation of cattle AIF-1 protein. Bovine AIF-1 gene was cloned into pET-32a plasmid and the recombinant plasmids (pET32a-AIF1) were transformed into BL21 (DE3) cells. Then bovine recombinant AlF-1 protein was purified using HisTrapTM HP and eluted by $100 \mathrm{mmol} / \mathrm{L}$ imidazole, then dialyzed into $10 \mathrm{mmol} / \mathrm{L}$ phosphate-buffered saline (PBS, $\mathrm{pH}=7.4$ ). Finally, the fraction with expected molecular weight (17 kDa) was detected by SDS-PAGE and indicated by an arrow. 
A

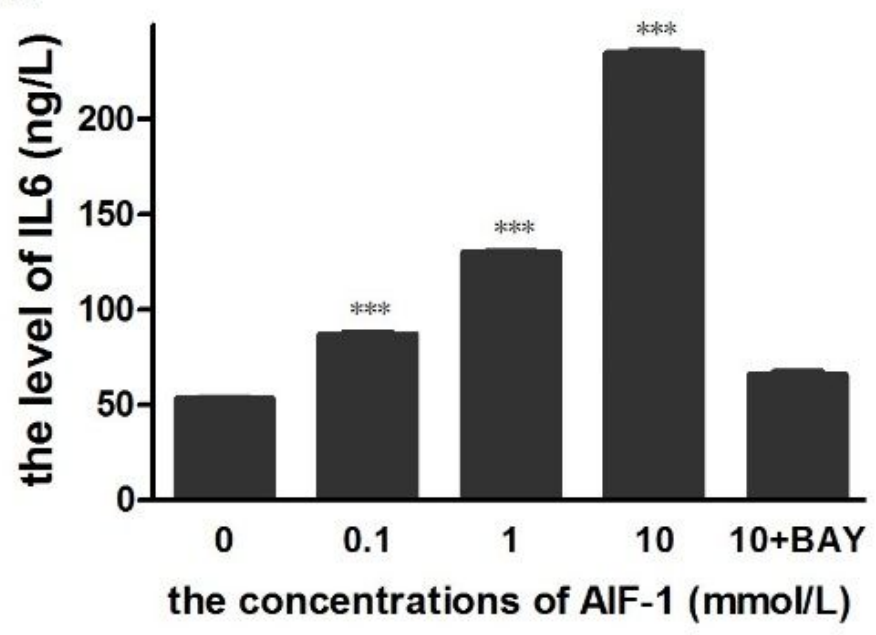

C

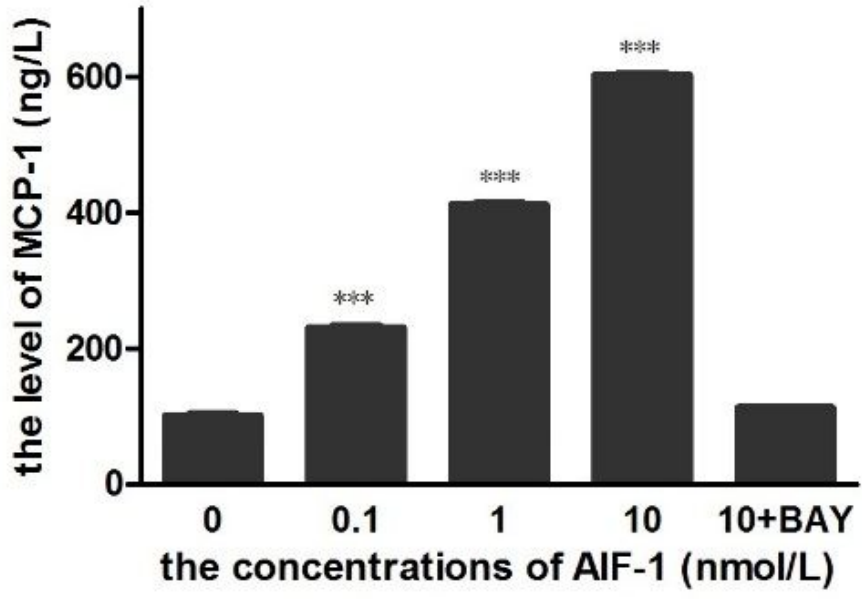

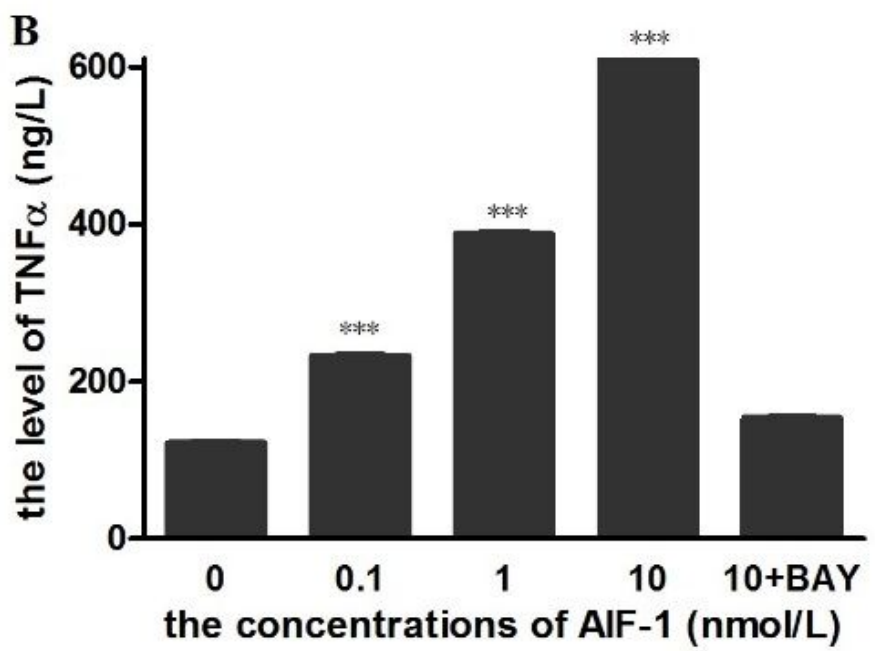

D

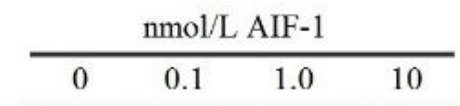

pIkBa

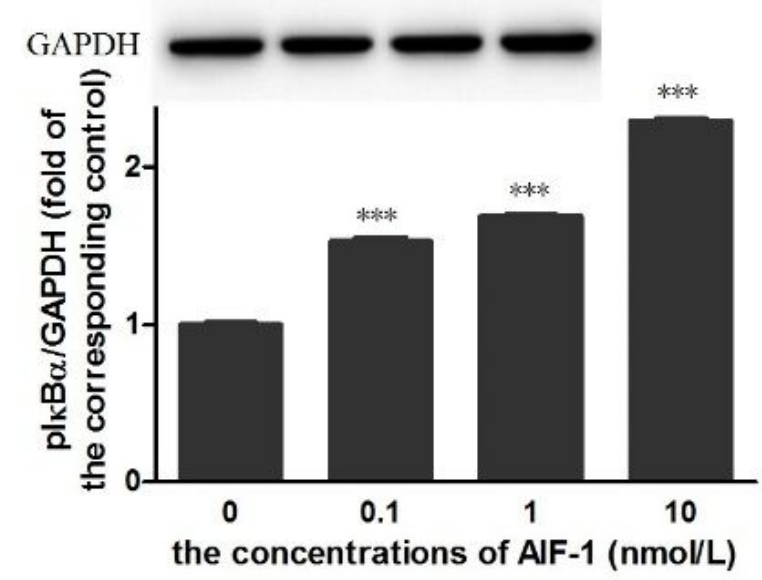

Figure 3

Inflammatory cytokines secretion from bovine mammary epithelial cells induced by AIF-1. The bovine mammary gland epithelial cells were exposed for 48 hours to $0,0.1,1,10 \mathrm{nmol} / \mathrm{L}$ AlF-1 or $10 \mathrm{nmol} / \mathrm{L}$ AIF1 supplemented with $2.5 \mathrm{mg} / \mathrm{L}$ BAY11-7085 in DMEM containing $10 \%$ fetal bovine serum. Then, the concentrations of IL6 (A), TNF- $\mathrm{a}(\mathrm{B})$ and MCP-1(C) secreted were measured using the corresponding ELISA kits. Phosphorylation of IKBa (Ser 32) was analyzed by western blot (D). Data were the mean \pm standard error of the mean of three independent experiments. $* \star \star P<0.001$. 

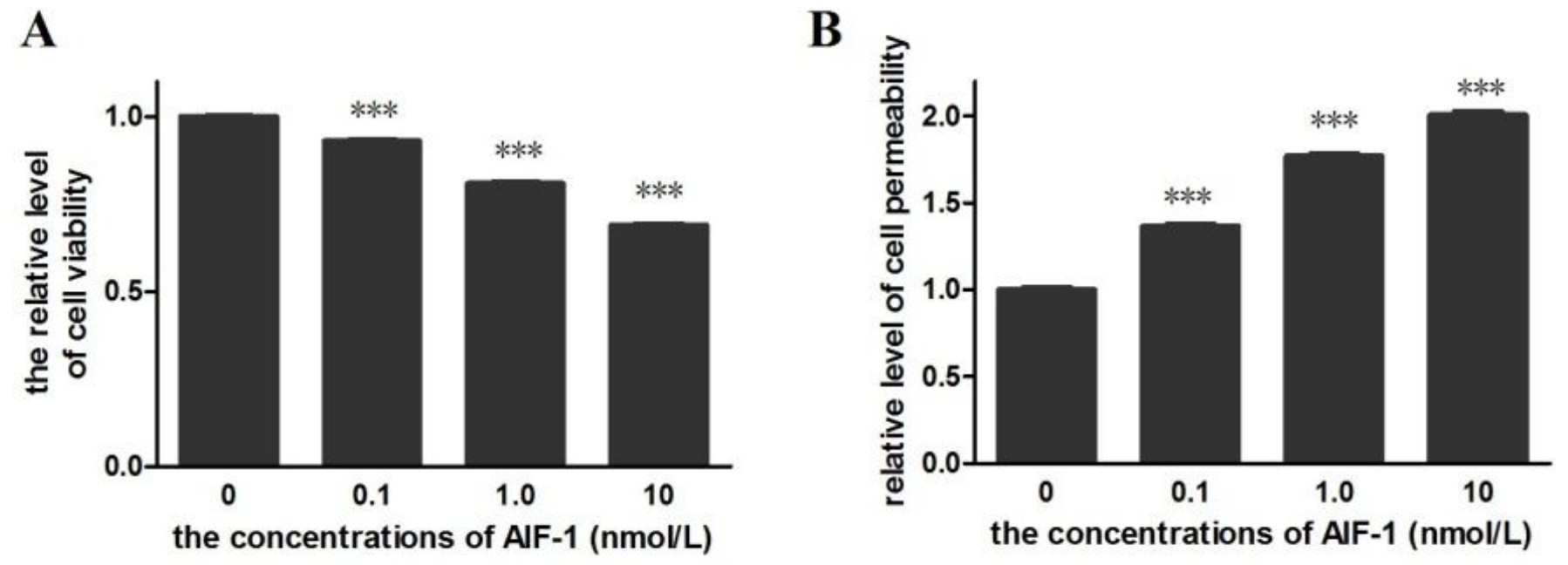

Figure 4

Viability and membrane permeability of bovine mammary epithelial cells. Cell viability was assayed by a cell counting Kit-8 (A) and membrane permeability was analyzed via lactate dehydrogenase release from mammary epithelial cells. The data were expressed as the percentage of viable cells and enzyme activity with AlF-1 treatment compared with that in control group, respectively. Data were the mean \pm standard error of the mean of three independent experiments. $* \star * P<0.001$. 

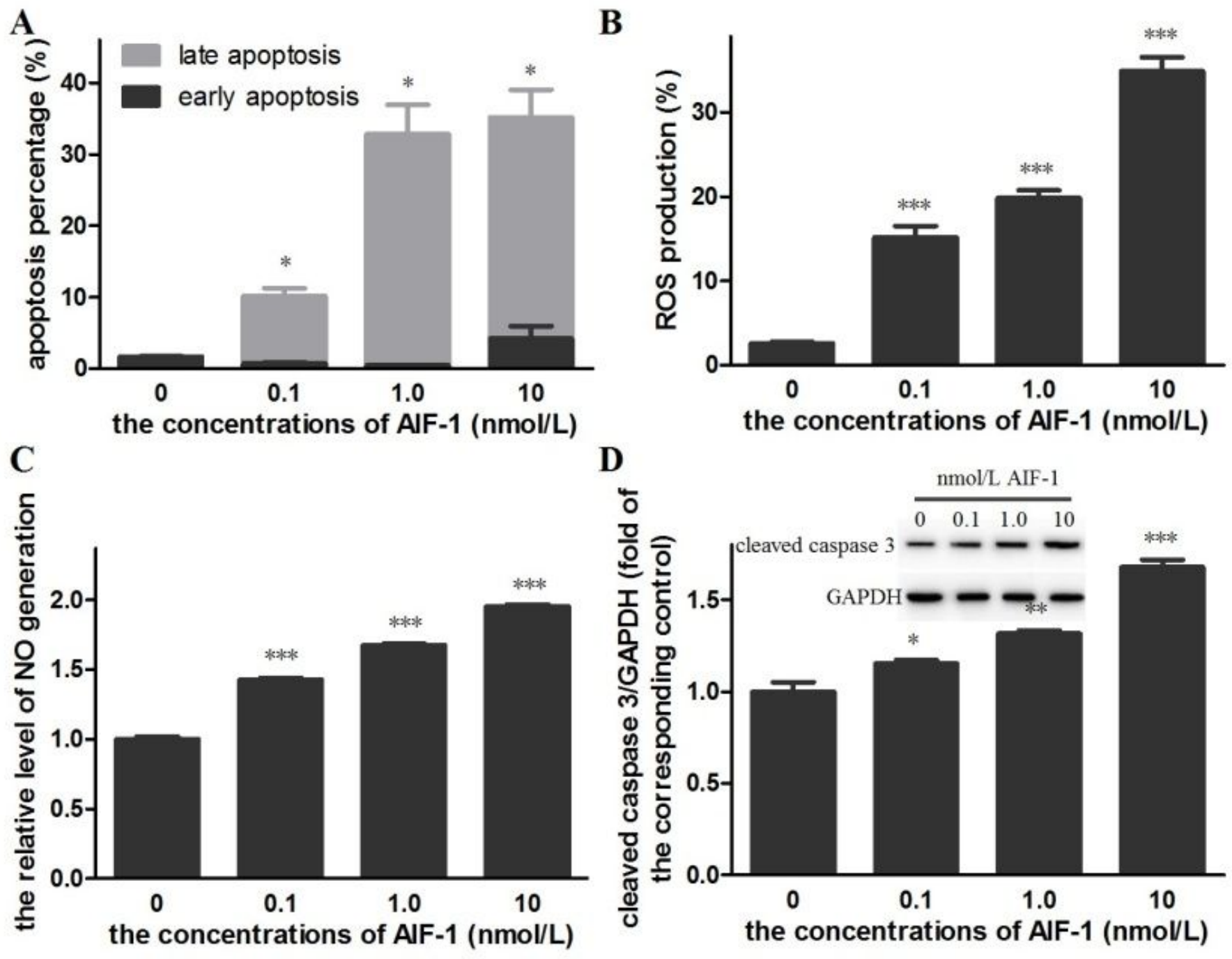

Figure 5

Cell apoptosis of mammary epithelial cells. After being treated with AlF-1 for 48 hours, mammary epithelial cells were stained and apoptosis was analyzed with an annexin V-FITC/PI apoptosis assay kit. The cell percentage of different apoptotic stages was determined by flow cytometer $(A)$. Reactive oxygen species (ROS) and nitric oxide (NO) generation was measured with cellular ROS detection assay kit (B) and NO quantitation kit (C). Cleaved caspase 3 (Asp175) was detected with western blot (D). Data were the mean \pm standard error of the mean of three independent experiments. ${ }^{*} P<0.05, * \star P<0.01, * \star * P$ $<0.001$. 
A

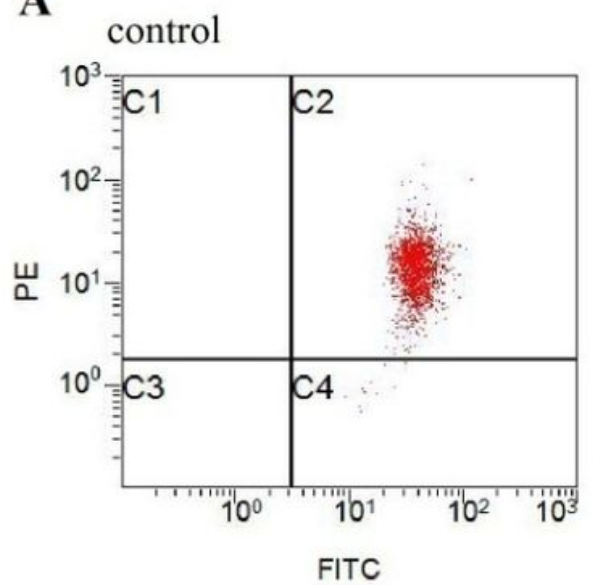

C

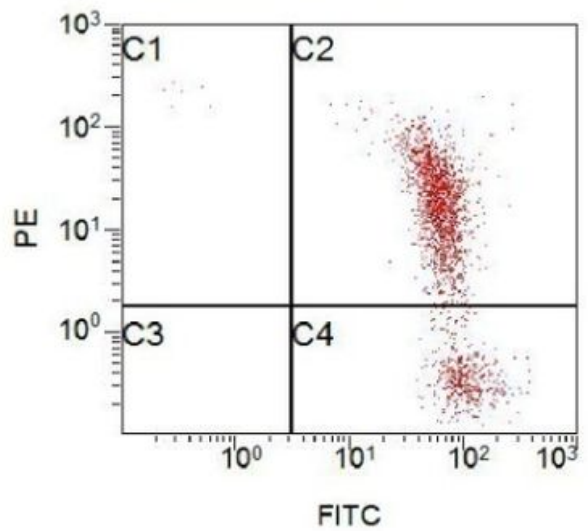

B

high mitochondrial membrane potential

(JC-1 aggregates)

low mitochondrial membrane potential

(JC-1 monomers)
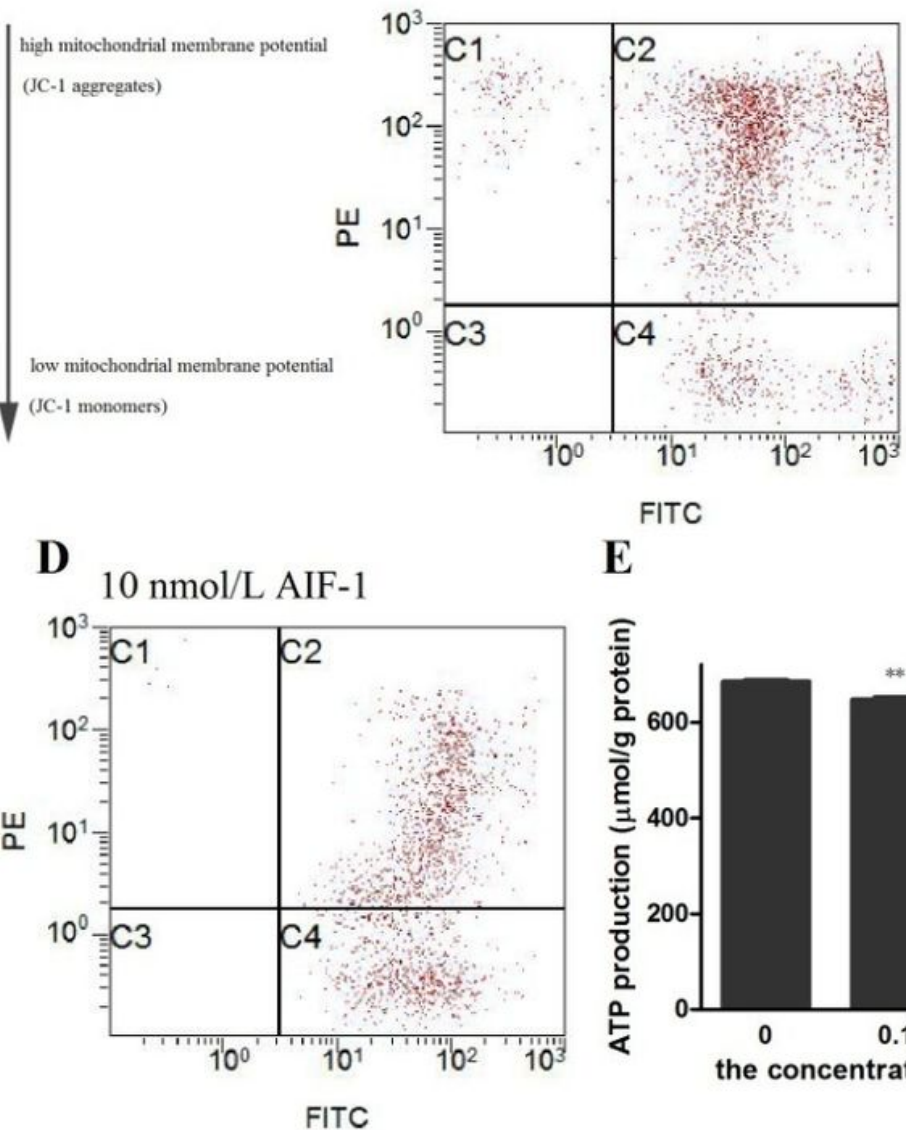

$\mathbf{E}$

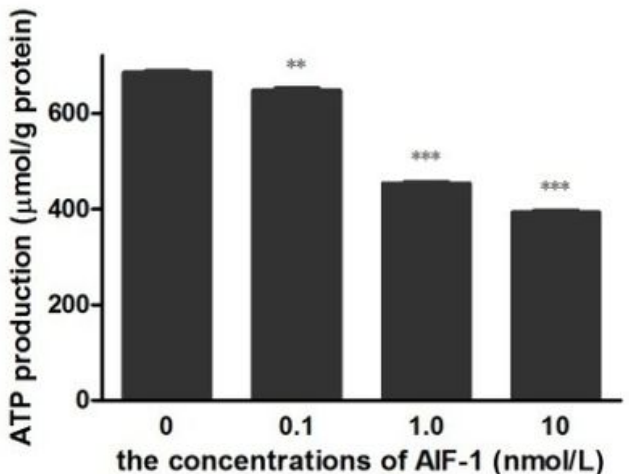

Figure 6

Mitochondrial apoptosis pathway of mammary epithelial cells. After $0,0.1,1,10 \mathrm{nmol} / \mathrm{L}$ AlF-1 administration for 48 hours. Mitochondrial membrane potential was estimated using fluorescent probe JC-1(A-D). Intracellular ATP concentrations were assayed with an ATP assay kit (e). Data were the mean \pm standard error of the mean of three independent experiments. ${ }^{\star \star} P<0.01$, ${ }^{\star \star \star} P<0.001$. 